\title{
AC 2011-1813: ENGINEERING ENROLLMENT RETENTION IMPROVE- MENT BY APPLICATION OF THE WRIGHT STATE MATHEMATICS EDUCATION MODEL
}

\section{Byron L Newberry, Oklahoma Christian University of Science and Arts}

Dr. Byron Newberry is Professor and Chair of Mechanical Engineering at Oklahoma Christian University. He holds a B.S.M.E. degree from Oklahoma Christian University and M.S. and Ph.D. degrees in Mechanical Engineering from The University of Michigan, Ann Arbor. His interests include stress analysis, nonlinear dynamics, structural vibration, and engineering design.

\section{Richard Miller, Oklahoma Christian University of Science and Arts}

Richard Miller joined the faculty of Department of Electrical and Computer Engineering at Oklahoma Christian University in 2005 after twelve years of industry experience. Dr. Miller earned his Bachelor of Science in Electrical Engineering (1987), Master of Science in Electrical Engineering (1989) and Doctor of Philosophy (1999) degrees from Texas A\&M University in College Station, Texas.

\section{Robert Andrew Stevenson, Oklahoma Christian University}

Robert Andrew Stevenson is a graduate level Engineering student at Oklahoma Christian University with a bachelors in Mechanical engineering from the same school. For his senior design project he and his team entered the regular class of the SAE Aero Design East competition and won first place in the presentation portion. After completing his masters he plans on entering into industry for a few years and then considering returning to school to pursue his doctorate degree. 


\title{
Engineering Enrollment Retention Improvement by Application of the Wright State Mathematics Education Model.
}

\begin{abstract}
At many universities around the country student retention within engineering disciplines is less than desirable. It has been observed that first year student dropout rates appear to correlate to individual performance in first-level calculus courses. In an effort to improve calculus performance, and thus continuing enrollment, in the fall of 2009 Oklahoma Christian University adopted aspects of the Wright State University model ${ }^{1}$ for mathematics education by introducing an introductory ENGR-1113 Foundations of Engineering Mathematics course as a prerequisite for first-level calculus enrollment. This course consists of both lecture and laboratory periods which are designed to strengthen basic algebra and trigonometry skills while also introducing students to foundational elements in calculus, differential equations and other higher-level mathematics.
\end{abstract}

The early part of the course is designed to cover trigonometric and algebraic fundamentals in order that students may review these basics necessary for upper-level mathematics and engineering courses. The later-half of the class is spent introducing basic concepts from higherlevel courses such as differentiation, integration, first and second order linear differential equations and linear algebra. Furthermore, the laboratory portion is designed to directly complement the lecture periods of the course as students apply that week's teaching directly to engineering models. This program inaugurates incoming engineering students by introducing applications of math within multiple disciplines of engineering.

Course success was initially examined by issuing a mid-term calculus readiness exam designed by the Oklahoma Christian mathematics department as well as examining student final class grades. After students who participated in the first incarnation of this course in fall 2009 completed their first-level Calculus course in the following spring, data was collected and student calculus grades as well as one year retention was compared to years prior. This is a discussion of the results of the programs implementation as well as notable variables and their possible effects on the course model after its first year of application. Herein also is discussed the possible benefits to engineering education programs as well as improvements adopted for the fall 2010 offering of the same ENGR-1113 Foundations of Engineering Mathematics course.

\section{Introduction}

Traditionally, engineering students begin their curriculum by completing a first level calculus course during the first year of their education before being able to begin sophomore-level engineering courses. A shocking percentage of these students do not make it to their second year within their chosen engineering discipline, either switching majors or leaving the university entirely. Dr. Nathan Klingbeil of Wright State University first observed that, traditionally, only $42 \%$ of engineering or computer science majors at Wright State advance beyond first-year calculus classes to seek their degrees 1. Thus, in an effort to improve student retention, in 2004 WSU under the care of Dr. Klingbeil developed a mathematics education model which is designed to incorporate a new introductory math course into the engineering curriculum to 
strengthen student math proficiency and introduce students to the engineering relevance of these skills 2-7. As part of the 2008 NSF CCLI Phase 3 initiative, 15 institutions across the country attempted an adoption of this model with the goal of improving student retention.

In 2008 Oklahoma Christian University, a faith based, private, ABET accredited institution located in northeast part of Oklahoma City, joined in the effort to combat low student retention by adapting the Wright State model as part of the 2008 NSF CCLI Phase 3 initiative. At the time of introduction the university had approximately 220 engineering students across three disciplines with roughly $32 \%$ represented by the freshmen class. Over $1 / 3$ of the engineering students enrolled at OC either change majors or leave the university within a year of beginning the program while the student graduation rate remains approximately $50 \%$. Thus, the desire to discover a remedy to this situation was the motivating factor in developing the introductory course ENGR-1113 Foundations of Engineering Math. The development of this course was a joint effort designed by the OC Department of Mechanical Engineering as well as the OC Department of Electrical and Computer Engineering. This course was introduced in the fall of 2009 and then continued in the fall of 2010.

\section{Course Objective}

This course was adopted into the required class structure for two primary purposes. Firstly, it is believed that by introducing a course specifically designed to improve student performance in calculus I it will, in turn, improve student one year retention and, ultimately, increase student probability of graduation. Secondly, the course is designed to improved student preparation and familiarity with mathematics topics and engineering methodology encountered within their entire educational career. It is believed that by improving the likelihood of success in calculus and student familiarity with engineering problem solving that student retention will be improved.

\section{Course Structure}

The course, labeled as ENGR-1113 Foundations of Engineering Mathematics, was instituted as a 3 credit-hour course consisting of a 50 minute twice a week lecture period as well as a once per week 3-hour lab. The course is a required first semester course for all engineering undergraduate programs. No student is exempt from completion of this course regardless of placement scores or previous mathematics experience or credits. A required minimum ACT math score of 23 was a prerequisite to enrollment for the 2009-10 academic catalog.

The lecture portion of this course was designed to cover mathematic basics as well as introducing students to their problem solving value for future coursework. This lecture portion of the class was conducted as one section while the conjoined laboratory portion was broken up into four sections, all limited to 20 students in order to ensure a more personal laboratory experience. The course was designed so that the content would have the most relevance to student's upcoming freshman and sophomore engineering courses. The breakdown of this course was as follows; three weeks of algebra, three of trigonometry, one week of matrix algebra, three weeks of calculus basics and three weeks of 1 st and 2 nd order linear differential equations. The laboratory experiments were designed to closely match the appropriate topics being covered in the lectures. A conscious effort was made to balance electrical and mechanical examples throughout the course lectures and laboratory experiments in order to appeal to a variety of 
student interests across the various disciplines. The laboratory was also geared to include a mixture of data acquisition methods and expose students to a variety of instrumentation and equipment. A summary of the class and lab material is shown in Table 1 and Table 2 below.

Table 1: Lecture course material breakdown

Subject

\begin{tabular}{|l|l|c|}
\hline Algebra & $\begin{array}{l}\text { Linear equations, quadratics, polynomials, basic conic } \\
\text { sections, roots, exponents and logarithms. }\end{array}$ & 6 Lectures \\
\hline Trigonometry & $\begin{array}{l}\text { Trigonometric functions, inverse trigonometric functions, Law } \\
\text { of Sines and Cosines, vector basics, complex number basics. }\end{array}$ & 5 Lectures \\
\hline $\begin{array}{l}\text { Matrix } \\
\text { Algebra }\end{array}$ & $\begin{array}{l}\text { Matrix notation, Cramer's Rule, determinates, matrix } \\
\text { inversion. }\end{array}$ & 2 Lectures \\
\hline $\begin{array}{l}\text { Calculus } \\
\text { Equations }\end{array}$ & $\begin{array}{l}\text { Dexivative basics, derivatives and integrals of polynomial and } \\
\text { exponts, max/min problems, integral basics, application of } \\
\text { integrals area and centroid problems. }\end{array}$ & 6 Lectures \\
\hline mechanical systems.
\end{tabular}

Table 2: Laboratory course material breakdown

\begin{tabular}{|c|c|c|}
\hline Subject & Material Covered & \# of periods \\
\hline Algebra & Simple Resistor Circuit, Resistors in Series and Parallel & 2 Labs \\
\hline Trigonometry & $\begin{array}{l}\text { Direct location and angle measurements on Articulated } 2 D \\
\text { Arm, Phase Shift in RC Circuit. }\end{array}$ & 2 Labs \\
\hline $\begin{array}{l}\text { Matrix } \\
\text { Algebra }\end{array}$ & Multiple loop circuit. & $1 \mathrm{Lab}$ \\
\hline Calculus & $\begin{array}{l}\text { Derivatives: Freefall Experiment Integration: Energy stored in } \\
\text { a spring. }\end{array}$ & 2 Labs \\
\hline $\begin{array}{l}\text { Differential } \\
\text { Equations }\end{array}$ & $\begin{array}{l}\text { 1st order equations: } R C \text { circuit response, Newtonian cooling } \\
\text { 2nd order equations: Oscillation of a spring-mass system }\end{array}$ & 3 Labs \\
\hline
\end{tabular}




\section{Course Evaluation}

Class evaluation was important in order to collect data on the performance of students and effectiveness of the class. Thus, after six weeks of covering algebra and trigonometric fundamentals, students were required to take a calculus readiness exam designed and written by the Oklahoma Christian Mathematics Department faculty. Upon passing this test students would then be allowed to enroll in calculus for the upcoming semester. Those not passing would be required to complete computer-based training in order to proceed directly into calculus. Those students who did not pass and did not complete the computer based training would be required to take College Algebra and/or Trigonometry.

Had the class not been offered to the 2009 OC freshman engineering class, based solely on ACT performance, $58 \%$ of the students would have been allowed to begin calculus immediately with the remaining $42 \%$ required to complete College Algebra and/or Trigonometry before proceeding. Based on the required criteria and the results of the fall 2009 offering of the class, ENGR-1113 Foundations of Engineering Math, 73\% of the freshman class completed the requirements and, thus, proceeded on to Calculus I.

At the end of the course student feedback was gathered by conducting a short survey which included questions on the students' view of how the course effected their motivation and confidence in future engineering and mathematics studies and the overall course relevance and worth. Free form comments were also accepted. It was observed that some students with strong incoming math skills resented being required to take the course; viewing it as remedial in nature. In contrast, students with low mathematics scores felt the material was covered too quickly. Overall students found value in the course as $71 \%$ submitted a neutral or positive response when asked if they believed that the course would increase their chance of success in engineering and $77 \%$ gave a neutral or positive response about whether or not they believed the course would increase their chance of success in future mathematics courses. A majority of students also felt the inclusion of differential equations to be not immediately relevant to upcoming courses.

\section{Analysis Results}

Following student completion of Calculus I in the spring of 2010, the student performance and enrollment data was collected and analysis was conducted to examine retention results. Student success probability in calculus for the freshman class of 2009 was examined in comparison to the previous four years of data available. After obtaining individual student performance results, an analysis was conducted to determine the distribution of Calculus I letter grades for the freshman class of 2009. These results were then compared to the average distribution of the previous four years (2005-2008). Figure 1 below shows a pie-chart of both the pre-2009 average letter grades in Calculus I as well as the 2009 class distribution. Although drastic variation is not evident it can be noted that an increase in student scores is observed (\% of A's) between the two charts but there is, in contrast, no clear decrease in the failure rate of students (students with D's and F's). 


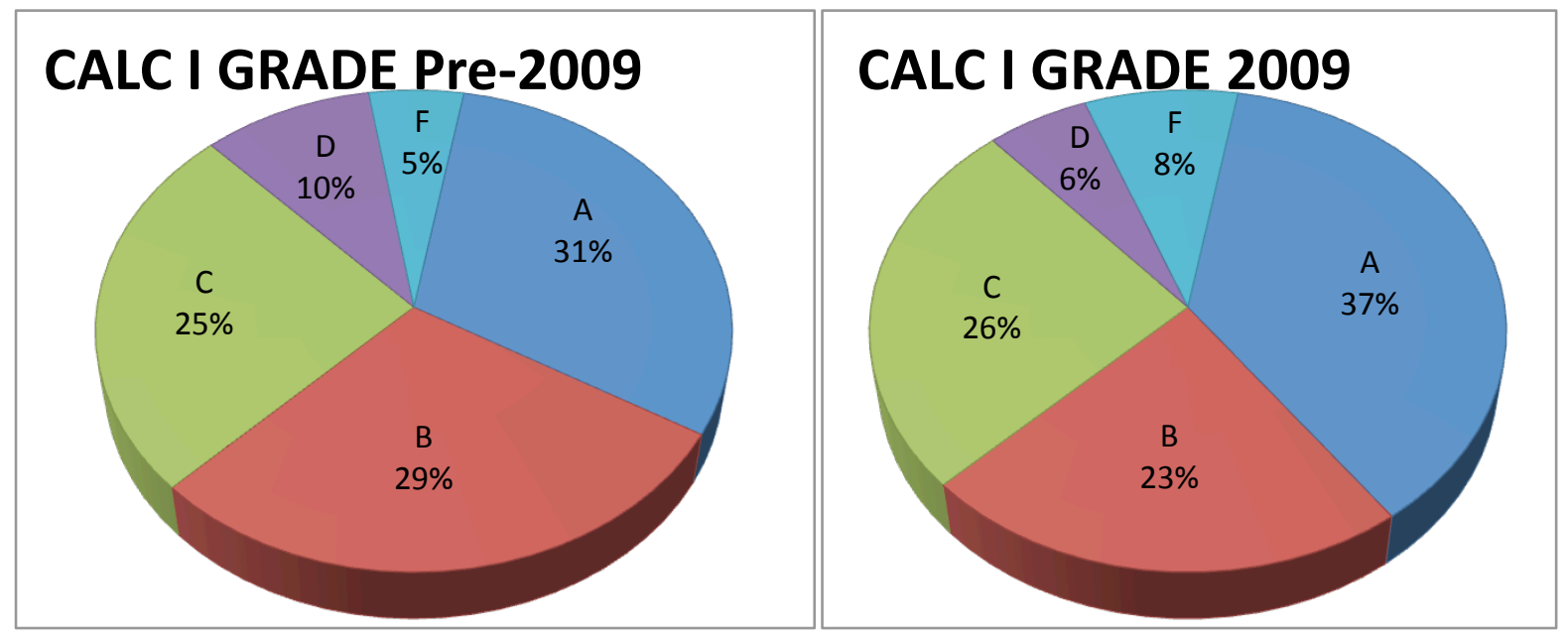

Figure 1: Calculus Grade Letter distributions

Next it was desired to examine student enrollment retention within the program in order to determine the class's possible benefit to student educational longevity. The 1 and 2 semester drop out numbers were tallied and then scaled to percentages based upon the class population size; the resulting bar chart in Figure 2 summaries the results.

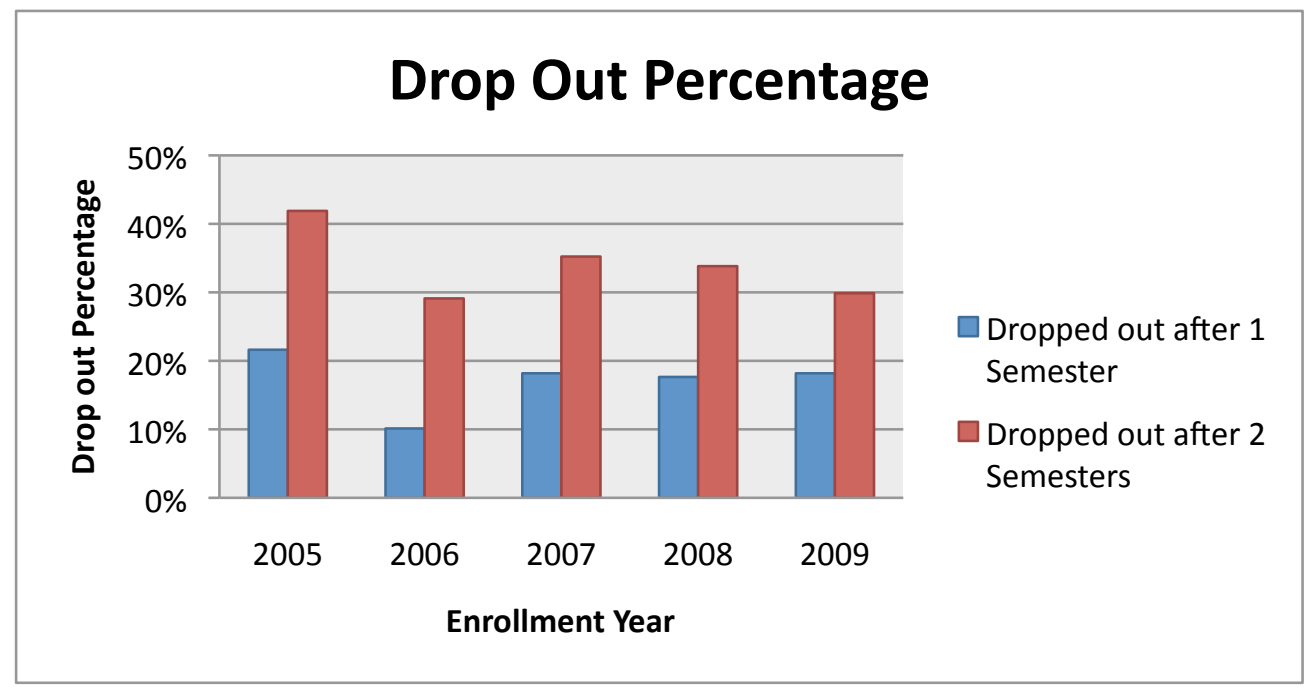

Figure 2: Drop out percentage bar chart from 2005-2009 for 1 and 2 semesters

The introduction of the course in 2009 appears to have a decreasing effect on drop-out rate as the percentage dropped after 2 semesters ( 1 year) was 30\% while the average rate across the four years was $35 \%$. This being said, it can be quickly observed that the drop-out rates across the spanning years appears to have enough variance to counter any definite conclusions. Also, as mentioned in a previous section, the downward trend of drop-outs in later years may be only the result of the introduction of a new scholarship system in 2008 which is structured to reward student longevity in the program. 
Following this, it was also desired to determine the predictability for student success in calculus based upon student performance in ENGR-1113 as well as the correlation between student ACT Composite and Mathematics scores and individual performance in calculus. Utilizing a discriminate analysis and comparing student final grades in ENGR-1113 Foundations of Engineering Math with corresponding final calculus grades it was determined that it can be predicted with $79.5 \%$ accuracy what a student's grade will be in calculus by examining their performance in ENGR-1113. It predicts based upon 3 group discriminate analysis that the grade a student will receive in calculus will most likely be the same as they received in the previous course. Thus, those who receive A's or B's in ENGR-1113 will receive A's or B's respectively in calculus with an almost $80 \%$ probability. In contrast, for students who receive C's or below in ENGR-1113 it can only be speculated with the same probability that they shall receive any grade below $\mathrm{C}$ in the impending calculus course.

\section{Conclusions}

Due to the availability of only one year's worth of data from the class's inception to-date, definite conclusions cannot be drawn; only speculated. Based upon the above analysis it appears that, although the introduction of ENGR-1113 does not cause mass improvement to calculus performance, it does suggest a positive effect in several areas. Firstly, although the freshman class of 2009 appears to have the same single semester drop-out rates as years previous, the two semester drop rates imply a decrease. It is possible that this is within variance between classes but it also may be the result of improved calculus performance. Secondly, it can also be inferred from the analysis of the data presented in Figure 1 that, although D's and F's in the course do not decrease the course mainly helps B students become A students.

\section{Modifications and Summary}

For the fall 2010 offering of ENGR-1113 Foundations of Engineering Math several alterations were made to the existing original class model in an attempt to further increase the course's effectiveness in equipping students with the necessary tools for future success. First, secondorder differential equations were removed from the course entirely in order to provide more class time to cover algebra, trigonometry and calculus topics.

Remaining major alterations to the course structure were made to the laboratory portion of the course. Firstly, all laboratory assignments were converted to a mastery approach. As student progressed through the labs they were required to receive instructor approval and a signature before proceeding. Students must obtain all required signatures in order to turn in the assignment for grading. Furthermore, laboratory assignments were improved based upon previous experiences during the fall 2009 offering. In addition, two previous labs were replaced in order to introduce two, LEGO Mindstorms based experiments designed to improve trigonometry and integration techniques as well as to increase student interest.

Based upon the results observed in the previous analysis as well as the evidences observed during both the 2009 and 2010 offering of the new introductory course, it has been decided that OC engineering students will continue to be required to take this course. The course appears to have value in increasing retention as well as individual performance of mid to higher level students. The class will continue to be modified and improved in order to determine the model 
which is best suited to serve the Oklahoma Christian community by increasing student math proficiency and cultivating the skills necessary for engineering students of all disciplines during their educational journey.

\section{Acknowledgements}

This work has been supported by the NSF Division of Undergraduate Education under the grant DUE- 0817332. Any opinions, findings, conclusions or recommendations expressed in this material are solely those of the authors.

\section{Bibliography:}

1. Klingbeil, N.W., Newberry, B., Donaldson, A., Ozdogan, J., "The Wright State Model for Engineering Mathematics Education: Highlights from a CCLI Phase 3 Initiative." Proceedings 2010 ASEE Annual Conference \& Exposition, Louisville, KY, June 2010.

2. Klingbeil, N., Rattan, K., Raymer, M., Reynolds, D. and Mercer, R., 2009, “The Wright State Model for Engineering Mathematics Education: A Nationwide Adoption, Assessment and Evaluation," Proceedings 2009 ASEE Annual Conference \& Exposition, Austin, TX, June, 2009.

3. Klingbeil, N., Rattan, K., Raymer, M., Reynolds, D., Mercer, R., Kukreti, A. and Randolph, B., 2008, "the WSU Model for Engineering Mathematics Education: A Multiyear Assessment and Expansion to Collaborating Institutions," Proceedings 2008 ASEE Annual Conference \& Exposition, Pittsburgh, PA, June, 2008.

4. Klingbeil, N., Rattan, K., Raymer, M., Reynolds, D., Mercer, R., Kukreti, A. and Randolph, B., 2008 “A National Model for Engineering Mathematics Education," Proceedings 2007 ASEE Annual Conference \& Exposition, Honolulu, HI, June, 2007.

5. Klingbeil, N.W., Mercer, R.E., Rattan, K.S., Raymer, M.L. and Reynolds, D.B., 2006, "Redefining Engineering Mathematics Education at Wright State University," Proceedings 2006 ASEE Annual Conference \& Exposition, Chicago, IL, June 2006.

6. Klingbeil, N.W., Mercer, R.E., Rattan, K.S., Raymer, M.L. and Reynolds, D.B., 2005, "The WSU Model for Engineering Mathematics Education,” Proceedings 2005 ASEE Annual Conference \& Exposition, Portland, Oregon, June, 2005.

7. Klingbeil, N.W., Mercer, R.E., Rattan, K.S., Raymer, M.L. and Reynolds, D.B., 2004, "Rethinking Engineering Mathematics Education: A Model for Increased Retention, Motivation and Success in Engineering," Proceedings 2004 ASEE Annual Conference \& Exposition, Salt Lake City, Utah, June, 2004. 